\title{
SESAME Equation of State Number 7100, Dry Sand
}

\author{
J. F. Barnes \\ S. P. Lyon
}

\section{DISCLAIMER}

\begin{abstract}
This report was prepared as an account of work sponsored by an agency of the United States Government. Neither the United States Government nor any agency thereof, nor any of their employees, makes any warranty, express or implied, or assumes any legal liability or responsibility for the accuracy, completeness, or usefulness of any information, apparatus, product, or process disclosed, or represents that its use would not infringe privately owned rights. Reference herein to any specific commercial product, process, or service by trade name, trademark, manufacturer, or otherwise does not necessarily constitute or imply its endorsement, recommendation, or favoring by the United States Government or any agency thereof. The views and opinions of authors expressed herein do not necessarily state or reflect those of the United States Government or any agency thereof.
\end{abstract}


SESAME EQUATION OF STATE NUMBER 7100, DRY SAND

by

J. F. Barnes and S. P. Lyon

\section{ABSTRACT}

A global equation of state (EOS) for a dry sand mixture at a grain density of $2.60 \mathrm{~g} / \mathrm{cm}^{3}$ has been constructed and placed on the SESAME library as material number 7100. A "sandstone" EOS can be generated by combining the present EOS with a suitabie EOS for water in the desired proportions. The hydrocode setup should then "low for the desired degree of porosity.

The chemical composition of the mixture of granular rock that we call "sand" obviously varies greatly with location. Although sand typically consists of well over 50 weight percent silica (as quartz, its high density form), there is an abundance of other oxides such as $\mathrm{Al}_{2} \mathrm{O}_{3}$, $\mathrm{Fe}_{2} \mathrm{O}_{3}$, and $\mathrm{CaO}$ nomally present in addition to a significant amount of water of hydration. (In the chemical analysis considered here, the organic matter present is also treated as water.) The particular mixture represented by EOS 7100 is given in Table $I$, where the data are taken from Vinogradov and Ronov. ${ }^{1}$ It should be pointed out that the table displays the results of chemical analyses, rather than the actual molecular species present in the undisturbed samples. For example, the $\mathrm{CaO}$ probably arises predominantly from the decomposition of limestore in 


\section{TABLE I}

Composition of Dry Sand as Used in EOS 7100

Minera l/Compound

$\mathrm{SiO}_{2}$

$\mathrm{Al}_{2} \mathrm{O}_{3}$

$\mathrm{Fe}_{2} \mathrm{O}_{3}$

$\mathrm{TiO}_{2}$

$\mathrm{CaO}$

$\mathrm{MgO}$

$\mathrm{K}_{2} \mathrm{O}$

$\mathrm{Na}_{2} \mathrm{O}$

$\mathrm{SO}_{3}$

$\mathrm{CO}_{2}$

$\mathrm{H}_{2} \mathrm{O}$
By Weight

$70.00 \%$

8. 22

4.53

0.58

4.25

1.89

2.06

0.58

0.69

3.87

3.02

.31
By Number

$68.34 \%$

4.73

1.67

0.43

4. 45

2.75

1.28

0.55

0.50

5.16

9.83

0.31 
the analyzed samples. The $\mathrm{CO}_{2}$ is mostly produced from 1 imestone and various other carbonate rocks. Because of the uncertain bound state of the chemical components of the mixture, clearly any equation of state that might be constructed is quite uncertain except at higher temperature where the relative atomic abundance is the only important factor. For this mixture the average atom, as used in the GRIZZLY ${ }^{2}$ EOS code, has a value of $\bar{Z}=y .549$ and $\bar{A}=19.124$, roughly $5 \%$ lower than for $\mathrm{SiO}_{2}$ itself. The grain density (reference density) is $2.60 \mathrm{~g} / \mathrm{cm}^{3}$, compared to $2.65 \mathrm{~g} / \mathrm{cm}^{3}$ for $\mathrm{SiO}_{2}$.

When shock data on the composite are lacking, as is the case at hand, a mixture EOS can, in theory, still be constructed by using any of a number of available "mixing prescriptions" on the aggregate of individual component EOSs. However, since we also lack. EOSs for several of the components, we used the following procedure:

1) We combined, using the "ideal mixing" option in GRIZZLY, the EOSs of the five most abundant components for which we had data: $\mathrm{SiO}_{2}, \mathrm{Al}_{2} \mathrm{U}_{3}$, $\mathrm{CaO}, \mathrm{Fe}_{2} \mathrm{O}_{3}$, and $\mathrm{H}_{2} \mathrm{O}$.

2) We obtained from this incomplete but representative mixture a calculated Hugoniot curve in the shock velocity-particle velocity $\left(U_{s}-U_{p}\right)$ plane and approximated it by four straight line segments.

3) We then used this result as part of the input to GRIZZLY for an average atom EOS calculation for the complete mixture as given in Table I.

The fit to the mixture Hugoniot is shown in Figure 1. It is apparent that the abrupt stishovite transition of quartz ${ }^{3}$ is rounded somewhat in the mixture, as would be expected, although both $\mathrm{CaO}$ and $\mathrm{Fe}_{2} \mathrm{O}_{3}$ display somewhat similar polymorphic transitions to that of quartz 
in their shock data. ${ }^{4}$ Parameters of the $U_{s}-U_{p}$ fit are given in Table II. Shock data were matched to the Thomas-Fermi-Dirac calculations at a compression of 1.85 .

The CHART JD nuclear model and generalized CHART D gamma, both due to J.D. Johnson ${ }^{3}$, were used. Gamma has the form

$$
\begin{array}{ll}
y_{1}(\eta)=y_{1}(\eta=\infty)+k_{11}(1 / \eta)+k_{21}(1 / \eta)^{2} & \eta \geq 1 \\
y_{2}(\eta)=y_{2}(\eta=0)+k_{12} \eta+k_{22} \eta^{2} & n \leq 1
\end{array}
$$

The $\mathrm{k}_{i j}$ are determined by the high and low density asymptotes and the right and left derivatives of $\gamma$ with respect to $\ln p$ at normal density. This form has the advantage that if $\gamma$ has structure as a function of density, as in the case with phase transitions, a more accurate representation can be obtained. The values of these parameters were taken to be the same as those used for polycrystalline quartz (SESAME 7383) as given in Ref. 3. The reference gamma, Debye temperature, and cohesive energy for the mixture were taken to be the weighted sum of the corresponding parameter values for each of the five major components. For each molecular species, the weight used was the normalized weight percent divided by the molecular weight. This method yielded a reference gamma of 0.857 , a Debye temperature of $849.4 \mathrm{~K}$, and a cohesive energy of 136.7 kcal/mole. In the cold curve construction, the Lennard-Jones factor was taken to be 0.25 , which resulted in a critical temperature of about $8500 \mathrm{~K}$.

Figure 2 depicts the calculated pressure isotherms over the entire temperature range of the SESAME library table. Note that the isotherms 


\section{TABLE II}

Approximate Shock Hugoniot as Used in EOS 7100

$$
U_{s}=c+s U_{p}
$$

\begin{tabular}{|c|c|c|}
\hline Doma in & c & s \\
\hline $0 \leq \mathrm{U} \cdot 0.774$ & 3.875 & 1.938 \\
\hline $0.774 \leq \mathrm{U}_{\mathrm{p}}<1.786$ & 5. 375 & 0.433 \\
\hline $1.786 \leq \mathrm{U}_{\mathrm{P}}<2.524$ & 5.813 & 0.762 \\
\hline $2.524 \leq U_{p}$ & 6.375 & 1.609 \\
\hline
\end{tabular}


selow the critical isotherm display van der Waals loops; this is the form in which the 301 table is stored on the SESAME library. For reference, we also show the corresponding isotherms with Maxwell equal-area construction in Figure 3. Data for effecting this replacement are stored in the 401 table of the library.

Figure 4 displays the energy isotherms.

A "sandstone" EOS can be generated by combining EOS 7100 with a suitable SESAME equation of state for water in the desired proportions. For example, we produced an EOS for a mixture of $97 \%$ by weight dry sand and $3 \%$ water to model sandstone with a total porosity of $15 \%, 45.6 \%$ of which is water saturated. In this case the dry bulk density is 2.21 $\mathrm{g} / \mathrm{cm}^{3}$ and the wet bulk density is $2.28 \mathrm{~g} / \mathrm{cm}^{3}$. In performing the mixing process we used SESAME 7153, a water equation of state essentially developed by Francis Ree of Lawrence Livermore National Laboratory. The calculated $U_{s}-U_{p}$ Hugoniot for the resulting sandstone mixture, shocked from its porous density of $2.28 \mathrm{~g} / \mathrm{cm}^{3}$, is shown in Figure 5 . A word of warning: the hydrocode setup may have to be altered to set pressure and energy at ambient values when initiating a run at a porous density less than the reference density of the SESAME table.

\section{REFERENCES}

1. A. P. Vinogradov and A. B. Ronov, Geokhimija (English Translation), No. 6, 533 (1956). It should be noted that the analysis was performed on deep core samples, and the mixture should more properly be called "dry sandstone". Sandstone is formed from sand by pressure and/or the injection of cementing materials; often the relative amount of such additive material is small.

2. J. Abdallah, Jr., "User's Manual for GRIZZLY," Los Alamos National Laboratory report LA-I0244-M (September, 1984).

3. See, for example, J. D. Johnson and S. P. Lyon, "EOS for Polycrystalline Quartz," Los Alamos National Laboratory report LA-10391-MS (May, 1985).

4. S. P. Marsh, editor, LASL Shock Hugoniot Data, U.C. Press (1980). 


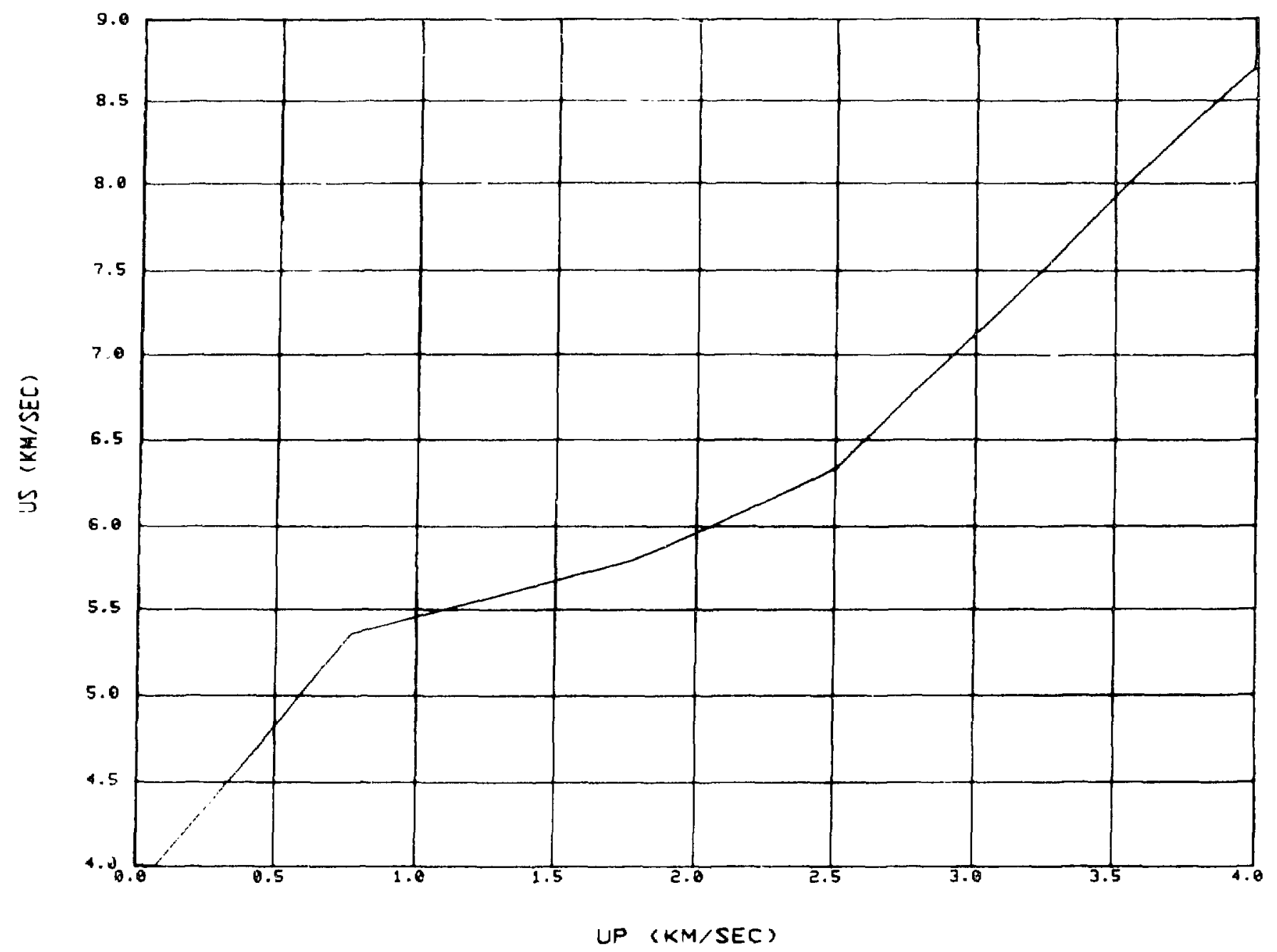

Figure 1.

Shock velocity versus particle velocity along the principal Hugoniot for EOS 7100 . 


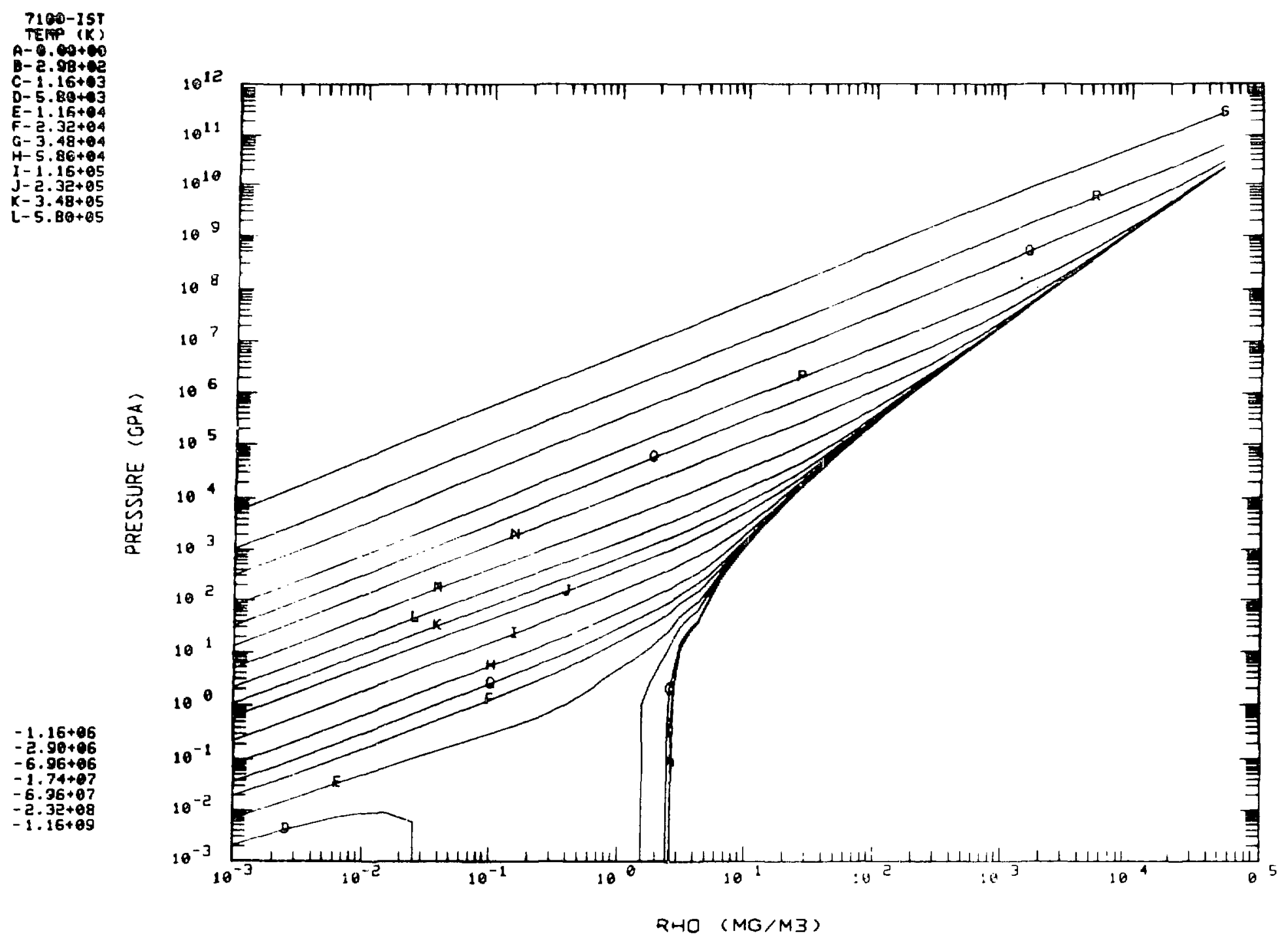

Figure 2. Selected pressure isotherms, containing the van der wal loops, for EOS 7100 . 


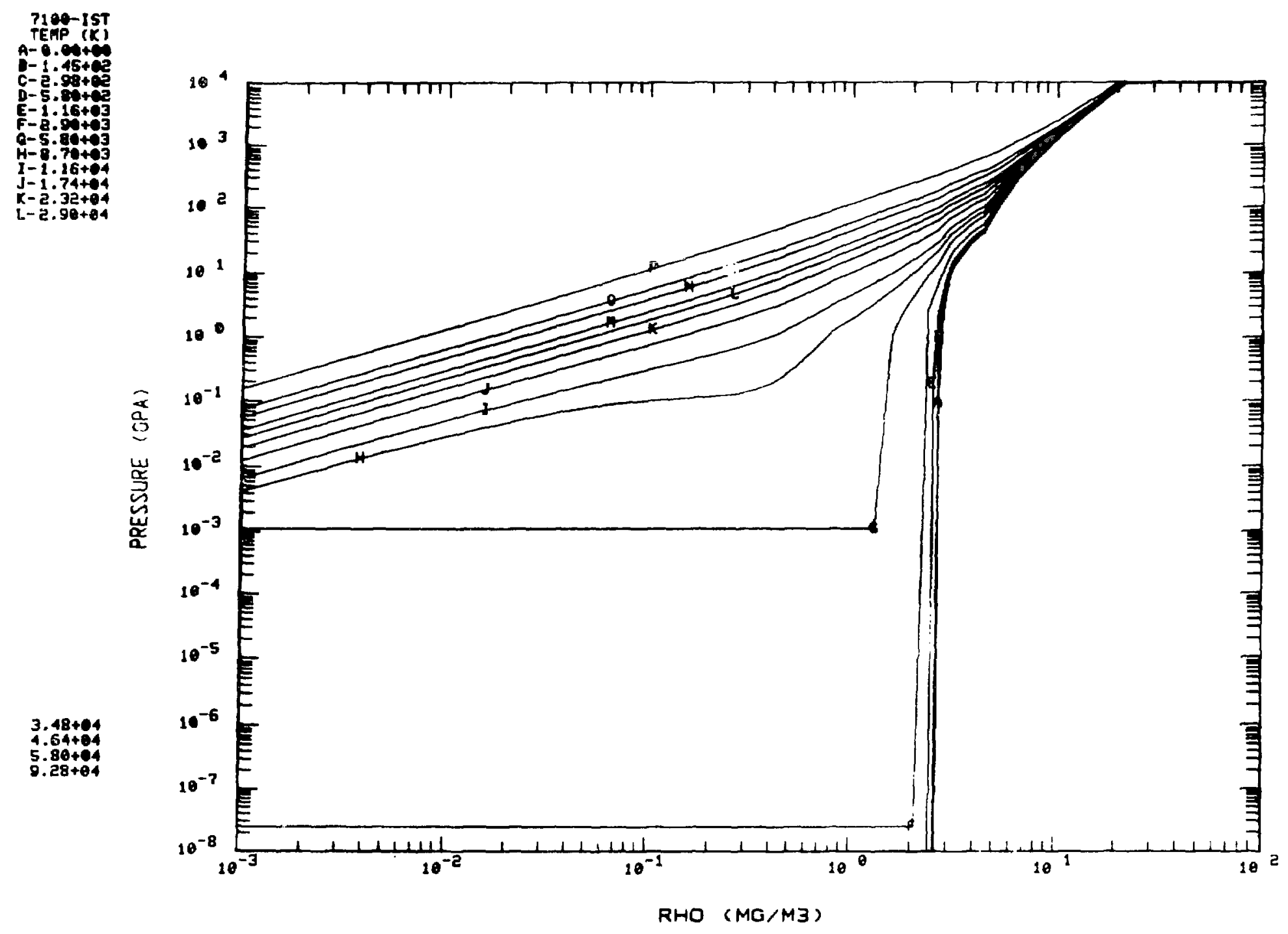

Figure 3. Selected pressure isotherms for EOS 7100 with van der Wal loops replaced by calculated equilibrium vapor pressure. 


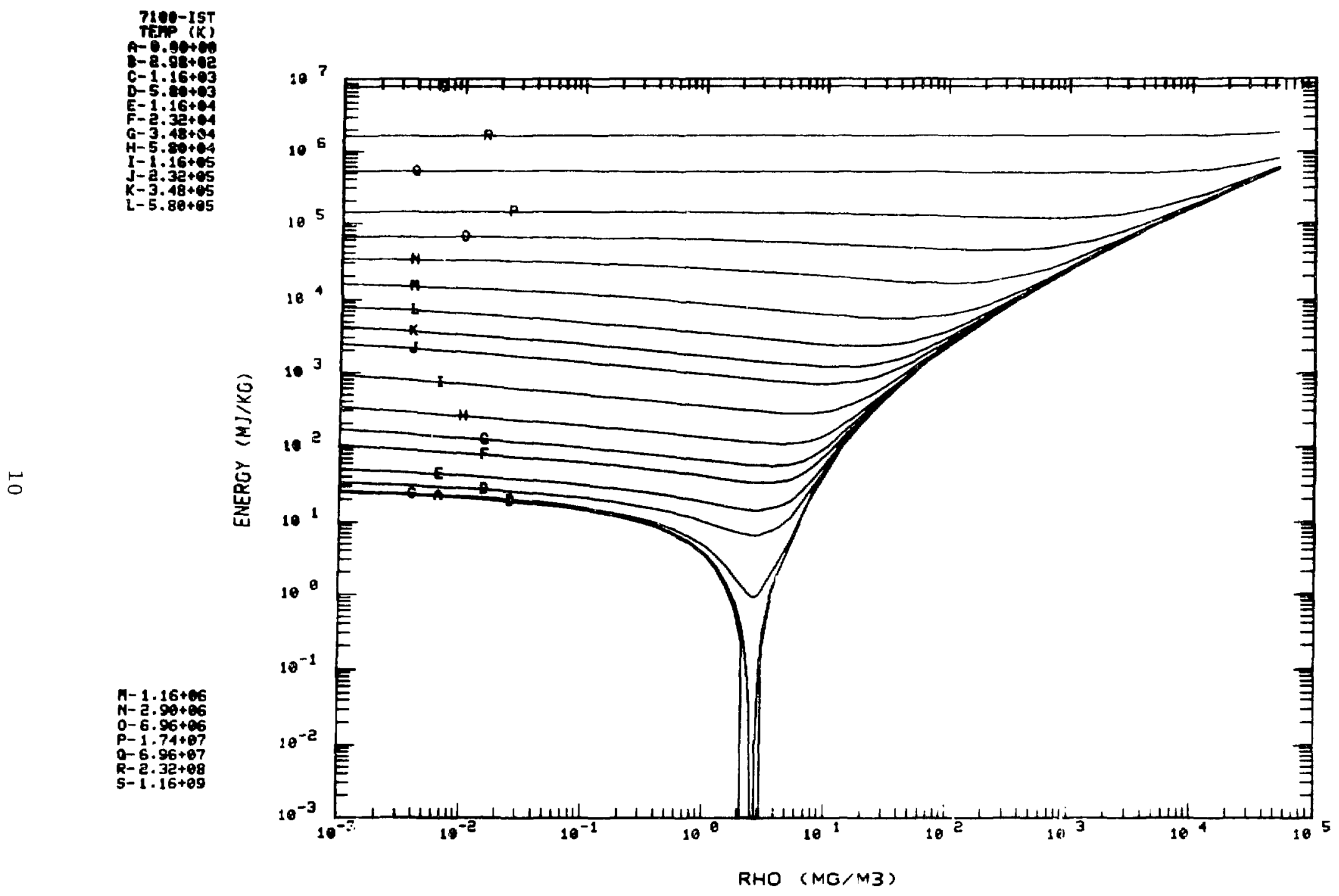

Figure 4. Selected energy isotherms for EOS 7100. 


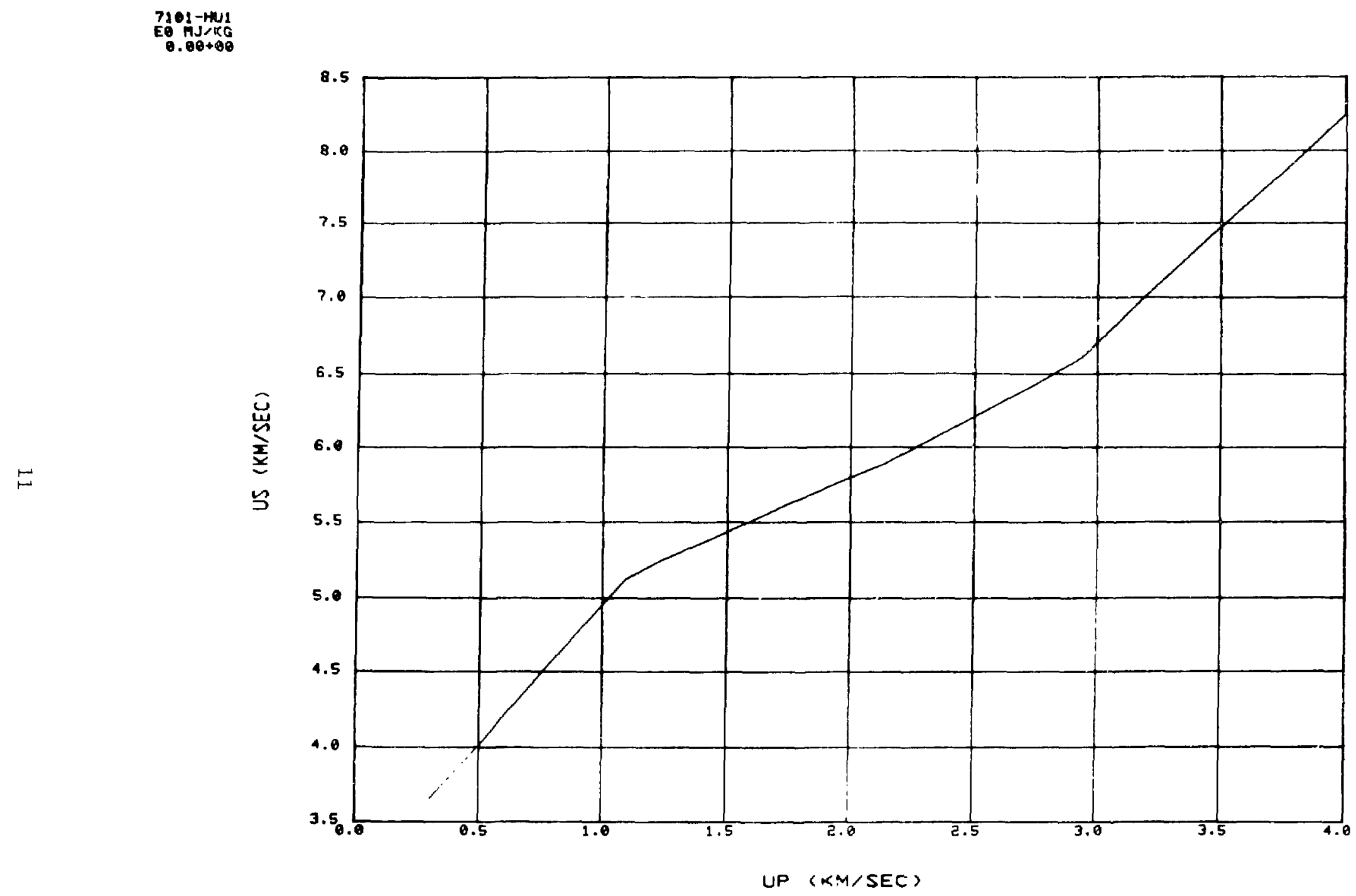

Figure 5. Calculated principal Hugoniot for sandstone with total porosity of $15 \%, 4 J .6 \%$ of which is water saturated. 